\title{
Estimation of Umbilical Artery Resistive Index in Pregnant Women with Preeclampsia in Al-Najaf Province
}

\author{
Basima Shamkhi Al-Gazali \\ Kufa University, College of Medicine \\ Saba Muhammed Jassim \\ Babylon University, College of Medicine \\ Abd Al-Aziz A.Aziz
Mosul University, College of Medicine \\ Raed F. Al-joubori \\ Al-Qasim Green University \\ sabamuhammed22@yahoo.com.
}

\begin{abstract}
This study was carried out on 105 pregnant women with preeclampsia in addition to 105 pregnant women without preeclampsia as a control at Al-Najaf province from September ,2017-May 2018. All the included patients were examined by Doppler study to assess the resistive index of umbilical artery $\mathrm{RI}$ in preeclamptic pregnant patients with $\mathrm{PE}$ and pregnant women without PE. The results reveals that there was significant difference of umbilical artery RI $0.658 \pm 0.304$, concerning preeclamptic pregnant patients in comparison to pregnant women without $\mathrm{PE}(0.571 \pm 0.215)$, ( $\mathrm{PV}$ lesser than0.05) .

In addition to that the umbilical artery RI was $(0.577 \pm 0.301)$ in preeclamptic pregnant patient with mild PE while it was $(0.813 \pm 0.247)$ in preeclamptic pregnant patient with severe PE which displayed a statistically significant difference( PV less than0.05).Also this study showed that the umbilical artery RI in preeclamptic pregnant patients with $H$. pylori was $(1.11 \pm 0.319)$ which was greater than that for preeclamptic pregnant patients without $H$. pylori $(0.919 \pm 0.25)$ with a statistically significant difference ( PV less than 0.5). It was concluded that Umbilical artery resistive index is a useful parameter in detection of preeclampsia and its severity and the umbilical artery resistive index might be useful parameter in prediction of infection of positive $H$. pylori infection associated with preeclampsia.
\end{abstract}

Key Wards: Resistive Index , Preeclampsia, Umbilical artery.

\section{Introduction}

Doppler study has been used widely for evaluating circulatory system in PE and it mean (i.e., resistance to pulsatile flow) (1).

Doppler waveform analysis is dependent on peak systolic frequency, enddiastolic frequency and average frequency. These three values are used to develop indices that reflect the pulsatility of the doppler waveform reflecting the dynamic changes in the circulation through the cardiac cycle. The frequently used obstetrical 
requests are the resistance index (RI) and peak systolic frequency shift to enddiastolic frequency shift ratio (2) that represents the change between the end-diastolic shift and peak systolic divided by the peak systolic shift (3).

Changes in blood flow in the fetus make doppler ultrasonography reveals these vascular changes linked with fetus compromise and allows prognosis prenatally. Enddiastolic flow velocity absence or reverse velocity of end-diastolic flow is linked with noticeably abnormal perinatal result chiefly higher prevalence of chromosomal abnormalities and a high perinatal mortality rate (4).

\section{Aim of study}

To assess the MCA RI in patients with preeclampsia and in relation to its severity and also its association with $H$ pylori.

\section{Materials and Methods}

\subsubsection{Patients and Controls:}

This is a prospective case-control study carried out in AL- Zahra Teaching Hospital from September 2017 till May 2018. The study included 210 pregnant women who attending the outpatient clinic and obstetric wards. The pregnant women included in the study divided into two groups:

1.Group I, include 105 preeclamptic pregnant patients who complained from upper abdominal pain and the following criteria have been used to establish the diagnosis of PE. The blood pressure is more than 140 of systolic blood pressure and more than 90 of diastolic blood pressure in addition to proteinuria happened beyond 20 weeks of GA agreeing to the criteria produced by College of America, Obstetricians and Gynecologists.

2.Group II, included 105 healthy pregnant women taken as control women that matched with age, trimester in addition to geographic location included in our study. The age of women participate in this study was between $18-40$ years for both groups.

\section{Determination of UmA by Doppler ultrasonography:}

The UmA Doppler study were performed in a positions that is semi recumbent and it considered abnormal if more $\mathrm{n}>2 \mathrm{SD}(5)$.

\section{Statistical Analysis}

Analysis of information statistically was performed by SPSS version 23. All results were presented as mean, SD and frequency. Independent sample t-test and One-way A Nova was used. PV was considered as statistically significant if its result was lesser than 0.05 . 


\section{Results}

Doppler Study:

Umbilical Artery Doppler study in pregnant women with/or without preeclampsia:

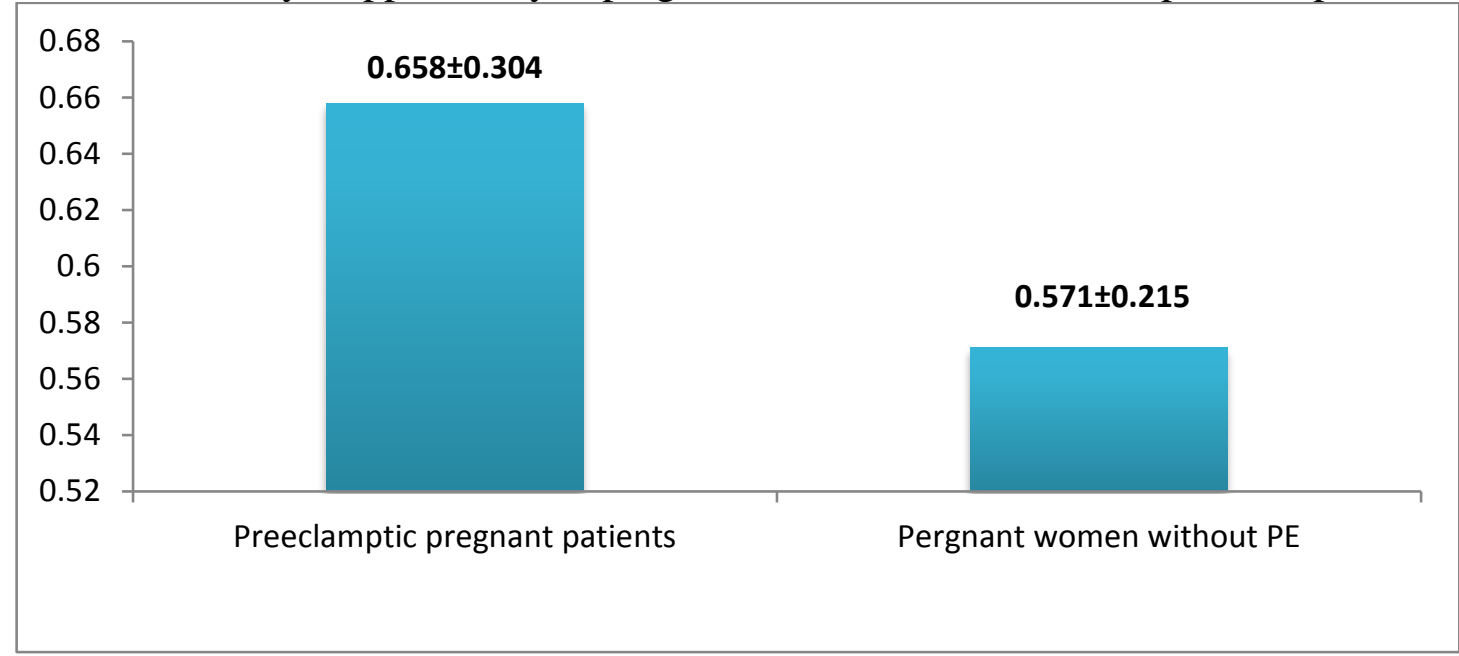

Fig. 1: Displayed umbilical artery RI in preeclamptic pregnant patients with $P E$ and pregnant women without PE ( PV less than0.05)

In this figure the umbilical artery RI in preeclamptic pregnant patients was greater than that for pregnant women without $\mathrm{PE}$ with a statically significant difference ( PV less than0.5). There was strong relationship between umbilical artery $\mathrm{RI}$ and PE.

Umbilical Artery Doppler study according to severity of preeclampsia:

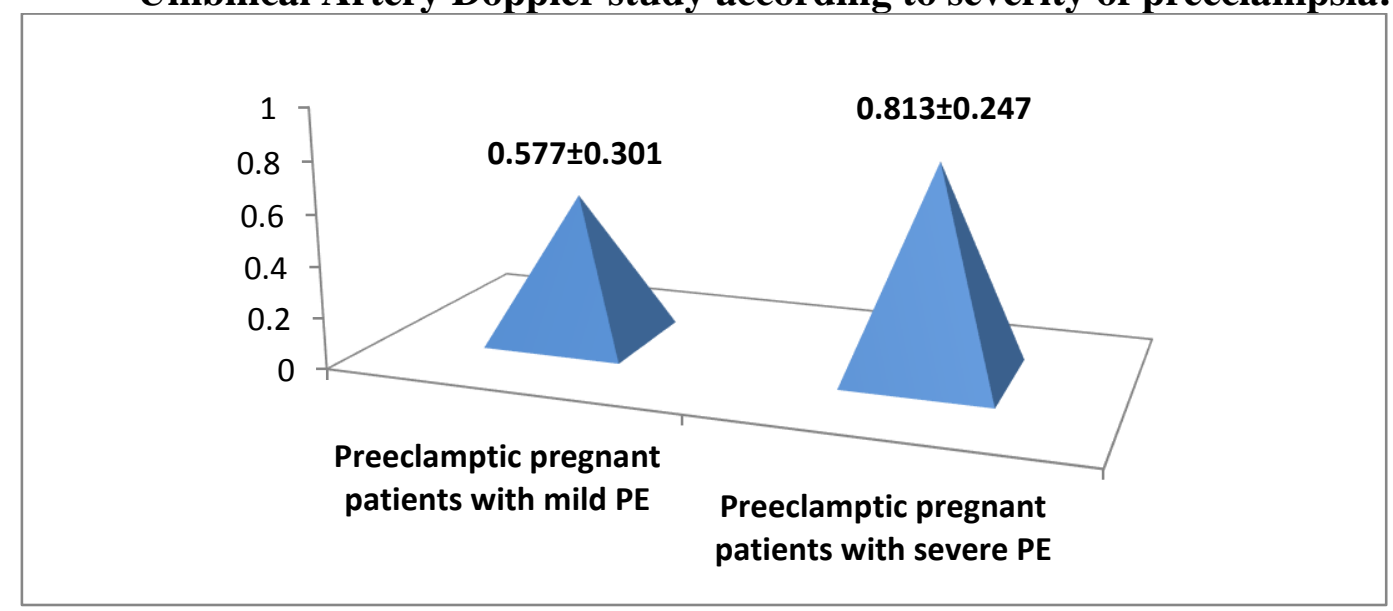

Figure 2: Displayed the umbilical artery $\mathrm{RI}$ in preeclamptic pregnant patients in relation to PE severity.

This figure displayed that the umbilical artery RI was $(0.577 \pm 0.301)$ in preeclamptic pregnant patient with mild PE while it was $(0.813 \pm 0.247)$ in preeclamptic pregnant patient with severe PE which displayed a statistically significant difference( PV less than0.05). There was strong relationship of umbilical artery RI among preeclamptic pregnant patients with mild PE in comparison to preeclamptic pregnant patient with severe PE. 
3. Umbilical Artery Doppler study in relation to $H$. pylori:

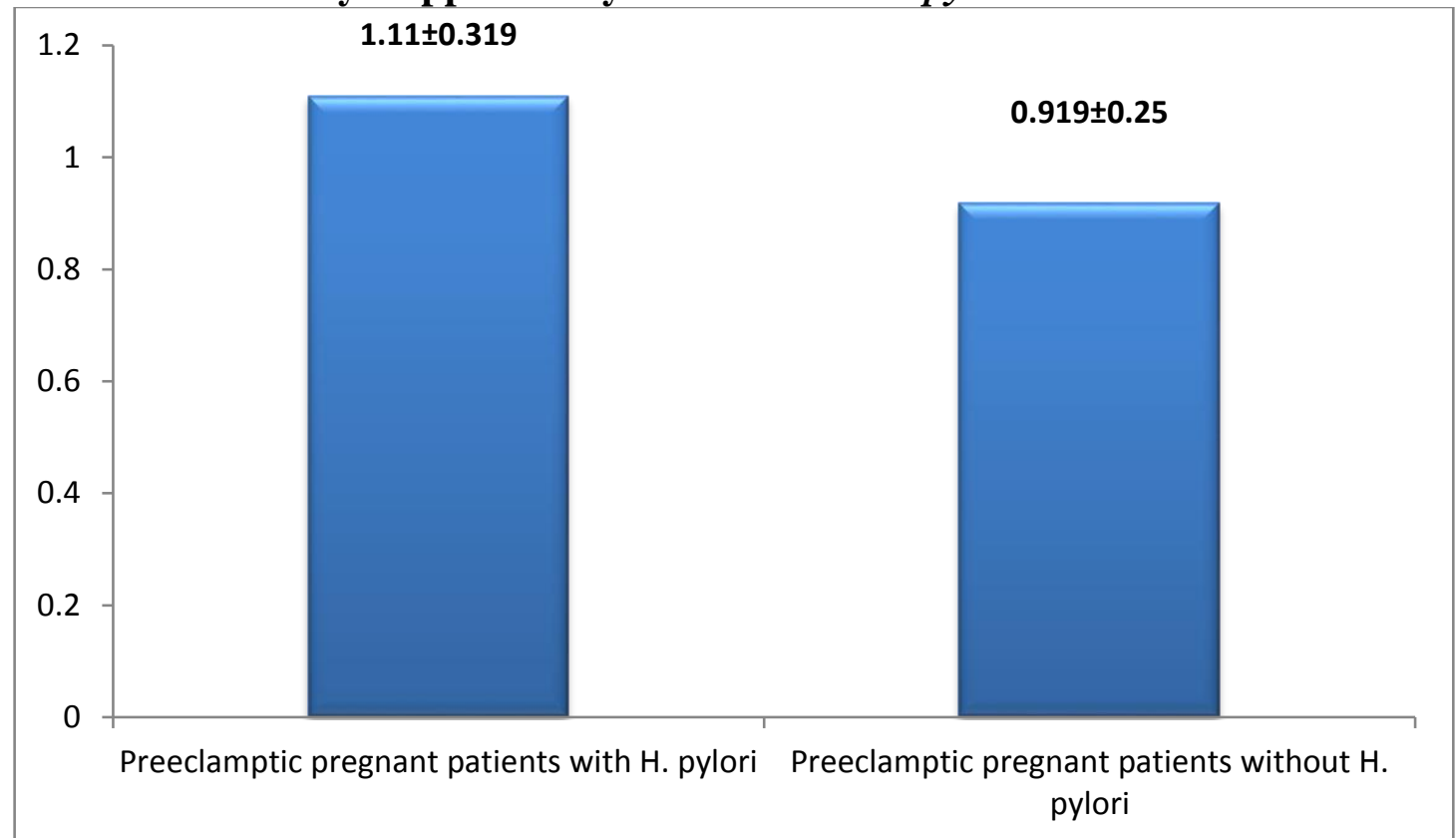

Figure (3): displayed the umbilical artery $R I$ in preeclamptic pregnant patient in relation to $H$. pylori serology

Fig. (3): displayed the umbilical artery RI in preeclamptic pregnant patients with $H$. pylori and preeclamptic pregnant patients without $H$. pylori. In this tab. the umbilical artery RI in preeclamptic pregnant patients with $H$. pylori was greater than that for preeclamptic pregnant patients without $H$. pylori with a statistically significant difference ( PV less than 0.5). There was strong relationship between umbilical artery RI and occurrence of $H$. pylori in PE.

\section{Discussion}

Figure (1) displayed a significant difference of umbilical artery RI concerning preeclamptic pregnant patients in comparison to pregnant women without PE ( PV lesser than0.05). There was significant elevation in umbilical artery RI in preeclamptic pregnant patients in comparison to pregnant women without PE group.

Also this study was consistent with Maged , 2014 who established that there was significant elevated in umbilical artery RI in comparison to pregnant women without PE ( PV lesser than0.05) (6). Also this study was agreed with Hala Metwally and Mohamed Orabi, 2015 study.

It was recently stated by L B James -Allan, 2018 that the range of announcement regarding the placenta with maternal decidua is important. In addition to that Adhera et al., 2014 displayed that the abnormal blood flow patterns in fetal circulation identified by high Doppler study of the umbilical artery may indicate poor fetal circulation, so this elevation might reflect there was significant reduction of blood flow to the fetus as a secondary cause to PE hence umbilical artery RI in PE can be regard as a extent of umbilical artery remodeling and assessment of umbilical artery might be a useful radiological parameter in patient with preeclampsia.

Figure (2) displayed Umbilical artery RI was significantly elevated in preeclamptic pregnant patients with severe PE in comparison to patients with mild PE( PV lesser than0.05). This reflect that there was strong relationship of Umbilical artery RI 
concerning preeclamptic pregnant patients with mild PE in comparison to pregnant with severe PE. Umbilical artery RI might be useful radiographic parameter that can be used to distinguish and monitor PE severity.

Radhwan M. H., 2016 who established significant difference in Umbilical artery RI concerning preeclamptic pregnant patients with mild PE in comparison to preeclamptic pregnant patients with severe PE in their study that was done at the Pediatric and Maternity Teaching Hospital in Hilla City. Antepartum assessment is based on the premise that identification and timed delivery of the hypoxic and acidotic fetus will prevent intrauterine fetal death and decline the risk of long term adverse effects. High flow resistance in the capillaries of the terminal villi leads to a low end-diastolic velocity in the umbilical artery and consequent hypoxia (7).

Fig. (3) displayed that the Umbilical artery RI was significantly elevated in preeclamptic pregnant patients with positive $H$. pylori serology in comparison to preeclamptic pregnant patients with negative $H$. pylori serology (PV lesser than0.05). This might be due to the fact that $H$. pylori might impairing placental development as it was stated by Di Simone N, 2017 that the H. pylori in preeclamptic pregnant patients will unavoidable to trophoblast (8).

H. pylori antibody will lead to cross reaction with human trophoblastic cells and a functional damage of cell invasiveness, thus, as long as the initial pathogenic model of $H$. pylori facilitated placental impairment. Subsequently in the primary course of fetal establishment and placental development, trophoblast invasion of maternal decidua is a vital stage, the planned autoimmune mechanism induced by $H$. pylori , adversely intrusive with the fetus horizontal line of the early developing Placenta.

\section{Conclusions}

1-Umbilical artery resistive index is a useful parameter in detection of preeclampsia and its severity.

2- Umbilical artery resistive index might be useful parameter in prediction of infection of positive $H$. pylori infection associated with preeclampsia.

\section{CONFLICT OF INTERESTS.}

There are non-conflicts of interest.

\section{References}

1. Mukhopadhyay A., Sharma P., Dasgupta S., Sharma PP. and Ghosh TK. (2012). Prediction of pre-eclampsia. comparative analysis of two screening tests. J Indian Med Assoc . 110:546-547.

2. Detti L., Akiyama M. and Mari G. (2002). Doppler blood flow in obstetrics.Curr Opin Obstet Gynecol. 14:587-593.

3. Harman CR. and Baschat AA. (2003). Comprehensive assessment of fetal wellbeing. which doppler tests should be performed? Curr Opin Obstet Gynecol. 15:147-157.

4. Abdulrazak H. Alnakash, Dr. Zena Abass Mushina, Abdulrazak H. Alnakash , Dr. Zena Abass Mushina , (2015 ). Relationship between PE umbilical blood flow and perinatal outcome International Journal of Scientific and Research Publications, Volume 5, Issue 12, December 2015465 :456-470.

5. Williams KP, Wilson S., (1995). Maternal cerebral blood flow changes associated with eclampsia. Am J Perinatol.12:189-91. 
6.Maged A M, Abdelhafz A Mostafa WAI. Fetal Middle cerebral and Umbilical artery Doppler after 40 weeks of gestational age. I Matern fetal Neonatal Med. 2014;27(18):1880-5

7. Radhwan M. Hussein1 MSc, Najat A. Hasan PhD, Bushra J. Al-Rubayae , (2016). Serum Soluble fms-like Tyrosine Kinase-1 (sflt-1) Level at Third Trimester of Pregnancy and One Month Following Delivery in Women with PE Iraqi JMS; Vol. 14(1).

8. Di Simone N., Tersigni C, Cardaropoli, S, Franceschi F, Di Nicuolo F, Castellani R, Bugli F, de Waure C, Cavaliere AF, Gasbarrini A, Sanguinetti M, Scambia G, Todros T, ( 2017). HP infection contributes to placental impairment in PE: basic and clinical evidences.Helicobacter.22(2).

الخلاصة

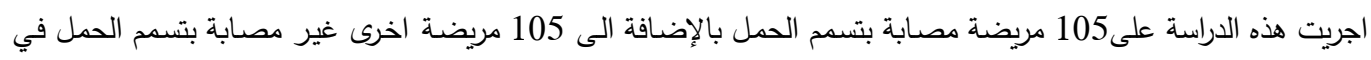

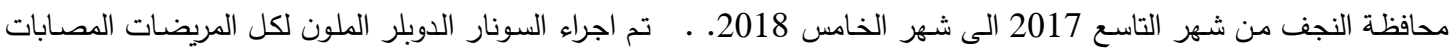

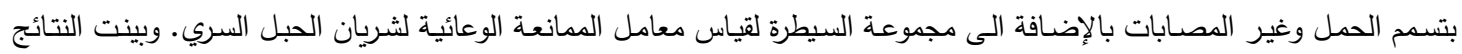

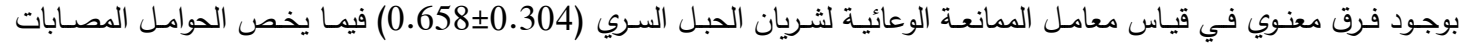

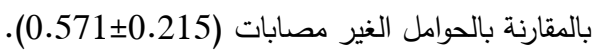

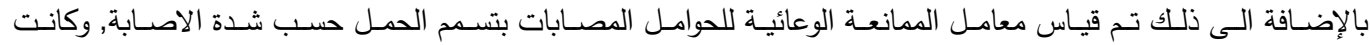

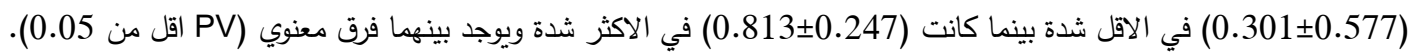
وكذلك هذه الدراسة بينت ان قياس معامل الممانعة الوعائية للحبل السري للحوامل المصابات بتسمم الحمل بالإضـافة الى اصلى الصابتها

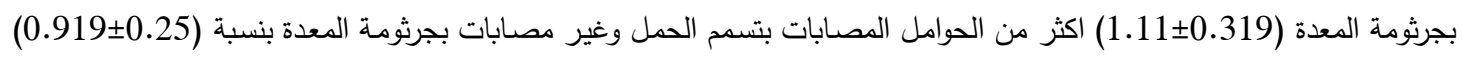

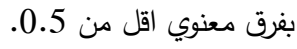

نستنتج من ذلك ان معامل قياس معامل الممانعة الوعائية لثريان الحبل السري ذا فائدة في تشخيص تسم الحمل وشدته وكذلك لـه

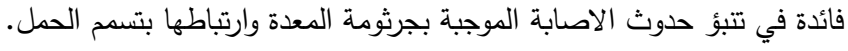
الكلمات المفتاحية: معامل الممناعة الو عائي, تسمم الحمل, الحبل السري. 